\title{
Epidemiology of prelingual sensorineural hearing impairment at a children's center in Bogotá, Colombia between 1997 and 2008
}

\author{
Claudia Talero-Gutiérrez, MD¹, Liliana Romero, MD², Irma Carvajalino, Audiol³, \\ Milciades Ibáñez, MSc ${ }^{4}$
}

\section{SUMMARY}

Introduction: Hearing loss is a frequent problem in childhood with an incidence of about one case per 1000 births. Control of deafness should be aimed at prevention and early diagnosis in efforts to provide appropriate treatment and stimulate adequate communication in children affected. The objective of this study was to determine the prevalence of different etiologies among deaf children with a diagnosis of prelingual sensorineural hearing loss referred to the Fundación CINDA in Bogotá, Colombia, between 1997 and 2008.

Materials and methods: The medical records were selected from those with prelingual hearing loss. Information was gathered in a format containing variables related to the risk factors suggested by the Joint Committee of Infant Hearing.

Results: We studied 254 children; boys and girls were equally distributed. The most common etiological diagnosis was «unknown cause», followed by genetic causes (31 cases), and 38 cases from TORCH infections (toxoplasmosis, others syphilis, rubella, cytomegalovirus, herpes), with rubella as the most common cause.

Conclusions: Review of prenatal, perinatal, and postnatal history often reveals the cause of the deafness in children; therefore, appropriate evaluation of pregnant mothers could result in decreased frequency of deafness in children in our country.

Keywords: Deafness; Sensorineural hearing loss; TORCH; Hyperbilirubinemia; Premature.

Colomb Med. 2011; 42: 199-206

Epidemiología de la pérdida auditiva neurosensorial pre-lingual en un centro de atención a niños de Bogotá, Colombia entre 1997 y 2008

\section{RESUMEN}

Introducción: La deficiencia en la capacidad auditiva es la alteración sensorial que con más frecuencia se encuentra en la literatura científica. La incidencia en la infancia es de un niño con pérdida auditiva profunda por cada mil recién nacidos. Los esfuerzos en el manejo de la pérdida auditiva deben estar orientados a la prevención primaria y a la detección temprana para estimular el desarrollo de la comunicación en los niños. El objetivo del presente trabajo fue establecer la prevalencia de los diferentes factores etiológicos en una población de niños sordos que asistieron a la Fundación CINDA, entre 1997 y 2008.

Material y métodos: Se seleccionaron las historias clínicas de aquellos con pérdida auditiva pre-lingual y se recolectó la información en un formato que contenía las variables relacionadas con los factores de riesgo planteados por el Joint Committee of Infant Hearing.

Resultados: Cumplieron el criterio de selección 254 niños (56.7\% niños y 43.3\% niñas). El diagnóstico etiológico más frecuente (47.2\%) fue desconocido, 31 casos se identificaron como genéticos y 38 tuvieron diagnóstico de STORCH (sífilis,

1. Professor, School of Medicine and Health Sciences, Universidad del Rosario. Neurosciences Research Group (NEUROS), Bogotá, Colombia. e-mail: claudia.talero@urosario.edu.co

2. Research Assistant, School of Medicine and Health Sciences. Universidad del Rosario. Neurosciences Research Group (NEUROS), Bogotá, Colombia. e-mail: liliromero.lopez@hotmail.com

3. Audiologist, Fundación CINDA, Bogotá, Colombia. e-mail: irmacarvajalino@gmail.com

4. Professor, Epidemiologist, School of Medicine and Health Sciences, Universidad del Rosario, Bogotá, Colombia. e-mail: milciades.ibanez@urosario.edu.co Received for publication October 27, 2009 
toxoplasmosis, rubeola, citomegalovirus, herpes), entre los que se encontró con mayor frecuencia la rubeola.

Conclusiones: Los antecedentes positivos de tipo pre $(63.4 \%)$, peri $(37.8 \%)$ y post-natal $(75.2 \%)$ permiten afirmar que un control adecuado del embarazo probablemente lograría disminuir en forma importante la incidencia de sordera en Colombia.

\section{Palabras clave: Sordera; Hipoacusia neurosensorial; STORCH; Hiperbilirrubinemia; Prematuro.}

Colomb Med. 2011; 42: 199-206

Deficiency in hearing capacity is the sensory alteration most frequently found in scientific literature. Its incidence in childhood is of one child with profound hearing loss per every thousand newborns ${ }^{1-3}$. The hearing impairment presented in this stage, prior to exposure to language, is denominated as pre-lingual; while that presented after having heard and even having developed language is denominated as post-lingual.

Epidemiological studies in Europe reveal that over $50 \%$ of the cases diagnosed correspond to genetic causes, while those related to events occurring during gestation or around birth, infectious, traumatic, or other post-natal processes correspond to the remaining $50 \%{ }^{1,3,4}$. The causes of hearing impairment have changed with infections being the least frequent in developed nations, whereas in developing nations they continue being a frequent risk factor ${ }^{3-5}$.

Epidemiological data from Latin America published by Madriz ${ }^{6}$ shows the lack of an adequately structured study in several of these countries. Nobrega et al. $^{7}$ at the pediatric otorhinolaryngology outpatient clinic at Universidad Federal de São Paulo, conducted a retrospective study and found that the etiology is unknown in most cases ( 190 of a total of 442 patients). Congenital rubella follows in importance with 67 patients, followed by genetic, perinatal causes, and meningitis ${ }^{7}$. Data analyzed by Madriz on Colombia refer to the 1993 Colombian population census with a prevalence of 5.2 individuals with hearing impairment per every 1000 births.

In Colombia, the technical reports from the Health and Education ministries and from the Instituto Nacional para Sordos (INSOR) refer to the etiology of hearing impairments as having perinatal origin in $52.5 \%$ of the cases, unknown in $40 \%$, and hereditary origin in $7.5 \%$. The consolidated analysis from the data base of the
Sistema Nacional de Información (National Information System) on the disability provides a prevalence of 12 per every thousand individuals with hearing loss, of which $18 \%$ present total hearing $\operatorname{loss}^{8}$. Mencher and Madriz ${ }^{9}$, calculated an incidence of 1.5 deaf children per every 1000 live births in Costa Rica.

According to the authors previously noted, between $38.75 \%$ and $50 \%$ of the diagnosed sensorineural hearing loss in children has no known cause. Some of these could have been infected with undetected cytomegalovirus (CMV). This infection has replaced meningitis as the cause of hearing loss; it is associated to progressive loss during childhood and it is one of the most frequent congenital infections in developed nations with incidences varying between $0.2 \%$ and $2 \%$. The effects of the congenital infection may vary from a congenital syndrome to an asymptomatic course. Five percent of children present damage to different organs, including the liver, spleen, cerebrum, eyes, and inner ear ${ }^{10}$.

Bacterial meningitis is another one of the frequent causes of sensorineural hearing loss, embracing $60-90 \%$ of post-lingual deafness ${ }^{11}$. In Colombia, the group led by Tamayo ${ }^{12}$ conducted a screening study, between November 2005 and May 2006, in the country's institutions for individuals with hearing loss. Ophthalmology studies were done on this population to detect «salt and pepper» retinopathy, typical of congenital rubella. A 33.5\% positive frequency for rubella was found in a population of 1383 subjects from the main cities in the nation. These results urge this group of researchers state that prevention measures are not being effective to diminish the presence of this type of pathology nor its detection. This group proposes a visual screening as a basic tool in studying the population with hearing loss.

Efforts to manage hearing loss are aimed -in the first place- at early detection to therapeutically intervene and stimulate development of communication in children. Said detection is done through the hearing screening, and monitoring of children from high-risk pregnancies. Screening programs have been evaluated to verify the early-detection feature, confirming better development of communicative abilities in children with early diagnosis ${ }^{12}$.

The Joint Committee of Infant Hearing identifies 11 risk factors of congenital permanent hearing loss, late onset or progressive, which are:

1. Concept of the parents or caregivers with respect to 
hearing, language, or retarded development.

2. Family history of permanent hearing loss.

3. Neonatal intensive care unit for a period over 5 days or less with requirement of assisted breathing, exposure to ototoxic medications or loop diuretics, and hyperbilirrubinemia requiring exanguinotransfusion.

4. Intrauterine infection (CMV, herpes, rubella, syphilis, toxoplasmosis).

5. Craniofacial anomalies that include the auricula, external hearing canal, tragus, and temporal bone anomalies.

6. Physical findings suggesting systemic entities associated to sensorineural or permanent hearing losses.

7. Syndromes associated to permanent or progressive hearing losses like neurofibromatosis, osteopetrosis, and Usher's syndrome.

8. Neurodegenerative disorders (Hunter's syndrome), sensory-motor neuropathies (Friederich's ataxia).

9. Postnasal cultures positive for infections associated to sensorineural hearing losses, including viral and bacterial meningitis.

10.Cranium-encephalic trauma (fractures of the base of the cranium, temporal bone) requiring hospitalization.

11. Chemotherapy ${ }^{13}$.

Morbidity of the population has varied in recent years as a consequence of greater numbers of people having access to vaccination schemes, prevention programs, and support to parents through healthcare community systems caring for children. However, it is not known what effect these measures have had upon the etiology of deafness nor upon what the priorities are regarding prevention programs according to the epidemiological variations.

The objective of the current study was to establish the prevalence of the different etiological factors in a population of children with hearing deficiency, who attended the Centro de Investigación e Información en Deficiencias Auditivas (Fundación CINDA) (Center for Investigation and Information on Hearing Deficiencies) from 1997 to 2008. This Foundation is a reference center for the diagnosis, rehabilitation, and adaptation of earphones and pre- and post-surgery intervention in the case of children who are candidates for cochlear implant.

\section{MATERIALS AND METHODS}

This is a correlation, descriptive, and retrospective study of children who attended the Fundación CINDA from 1997 to 2008. The inclusion criteria were the diagnosis of prelingual sensorineural hypoacusis; the exclusion criteria involved hearing losses of conductive or mixed type and post-lingual origin. Some 254 clinical charts were sequentially selected from those complying with the selection criteria.

Information was gathered in a format containing variables that evaluated family antecedents, presence of prenatal alterations like infectious processes, taking of ototoxic medications; perinatal alterations like weeks of gestation, hypoxia or suspicion of fetal suffering, and postnatal alterations of infectious and medication type and syndromes associated to hypoacusis and others related to the risk factors suggested by the Joint Committee of Infant Hearing. A previous pilot test was carried out.

The information was systematized on an Excel 2007 data base. This work was carried out by a general physician, a speech therapist, and medical students who received prior training in handling clinical charts and in the search and selection of data to be analyzed.

For data quality control and to avoid bias, we kept in mind the confirmation of the hearing loss secondary to a sensorineural deficiency and not to conductive processes; clinical charts without complete information were excluded and the information was purged with logical frequencies and cross-referencing to identify inconsistencies in the information gathered.

Statistical analysis. Information was processed in SPSS version 16 and STATA 10 statistical packages. In the description of etiological factors in general, in qualitative variables, measurements of absolute and relative frequencies were established expressed in percentages, and in quantitative through measurements of central tendency with the average, median, and dispersion, the range and standard deviation.

For the purpose of evaluating the association between etiological factors and sex and the magnitude of hearing loss, we used Pearson's Chi square test of association or the likelihood exact tests and Fisher's (expected values $<5)$. These tests were evaluated at a $5 \%(\mathrm{p}<0.05)$ significance level.

Ethical aspects. Each patient was assigned an 
Table 1 Classification of the degree of hypoacusis*

\begin{tabular}{lc}
\hline \multicolumn{1}{c}{ Degree } & dB HL \\
\hline Normal hearing & $0-10$ \\
Minimum hypoacusis & $11-25$ \\
Slight hypoacusis & $25-40$ \\
Moderate hypoacusis & $40-55$ \\
Moderate to severe hypoacusis & $55-70$ \\
Severe hypoacusis & $70-90$ \\
Profound hypoacusis & $\geq 90$ \\
\hline
\end{tabular}

${ }^{*}$ Ross and Downs, 2004 - ANSI 1996

identification code to maintain the confidentiality of the information. This study was classified without risks according to norms established by resolution 008430 of 1993 by the Ministerio de Salud de Colombia (scientific, technical, and administrative norms for health research). The recommendations of the Helsinki Declaration by the World Medical Association were followed. It was a study of observational design and lacking of direct intervention with the children. Upon admission to the institution, all parents signed an authorization letter, which permits using the information related to their children in teaching and research activities. This was done bearing in mind the functions of the Fundacion CINDA, from the care, academic, research, diffusion, and social sensitivity points of view. This study was approved by the Ethics Committee of the School of Medicine and Health Sciences at Universidad del Rosario.

\section{RESULTS}

The total population completing the selection criteria was 254 patients of which 144 (56.7\%) were boys and 110 were girls (43.3\%). The minimum age to enter the study was 2.5 months, and a maximum of 16 years of age with an average of $3.7 \pm 2.7$ years. The degree of hearing loss was classified according to 1996 ANSI criteria, presented by Ross and Downs ${ }^{14}$, and bearing in mind the configuration of the audiometric curve by frequency ranges (Table 1).

The audiological diagnosis carried out in the population revealed profound hypoacusis of the right
Table 2 Family antecedents

\begin{tabular}{lc}
\hline Positive antecedents in 55.5\% (141 cases) & \% \\
\hline Neurological pathology & 19.3 \\
Delayed language & 18.5 \\
Hypoacusis & 16.1 \\
Psychomotor development & 6.3 \\
\hline Alcohol and psychoactive substances & 6.7 \\
Psychiatric & 6.7 \\
Language alteration & 6.1 \\
High blood pressure & 3.5 \\
Cancer & 3.5 \\
Diabetes mellitus & 2.8 \\
\hline
\end{tabular}

ear in 126(49.6\%) of the children and severe to profound hypoacusis in $53(20.9 \%)$. For the left ear, profound hypoacusis was found in $129(50.8 \%)$ children and severe to profound hypoacusis in $51(20.1 \%)$ children. Hearing loss was severe in the right ear for $32(12.6 \%)$ children and in the left ear for $31(12.2 \%)$ children. In total, 211 children were classified in the highest levels of hearing loss.

The minimum age for the mother at the moment of giving birth was 13 years of age; the maximum was 44 years of age with a mean age of $25.6 \pm 6.5$ years.

In 141 children (55.5\%), some type of positive family antecedent was found (Table 2) among which it is worth remarking hearing loss, delay or other type of language alteration, psychomotor delay, and neurological pathology.

Prenatal antecedents were positive in $161(63.4 \%)$ cases (Table 3 ). In these, it is important to note the frequency of infection during pregnancy by agents like rubella, syphilis, toxoplasmosis, and cytomegalovirus, which constituted $15.7 \%$ of the cases. There were 10 children with other infections not classified at the moment of doing the clinical history, among which any of the aforementioned agents may be found.

Threat of abortion, hypertension, and ingestion of prescribed medications, including antibiotics, and urinary infection were the most frequent adverse events during gestation.

Among the perinatal antecedents, positive in 96 $(37.8 \%)$ of the population studied, it was found that in $7.4 \%$ of the children under 30 weeks of gestation and 
Table 3

Prenatal antecedents

\begin{tabular}{lrr}
\hline \multicolumn{2}{c}{ Positive antecedents in 63.4\% (161 cases) } \\
\hline & $\mathbf{N}^{\circ}$ & \% \\
\hline STORCH & & 15.7 \\
Rubella & 30 & \\
$\quad$ Syphilis & 4 & \\
Toxoplasma & 2 & \\
CMV & 1 & \\
Herpes & 1 & \\
Gestational HTA & 37 & 14.6 \\
Pharmacological & 37 & 14.6 \\
Threat of abortion 1st trimester & 26 & 10.3 \\
Direct trauma & 24 & 9.5 \\
Urinary infection during gestation & 24 & 9.5 \\
Maternal-fetal incompatibility & 12 & 4.8 \\
Others eruptive & 10 & 3.9 \\
Radiation & 6 & 2.4 \\
Premature membrane rupture & 5 & 2 \\
Oligoamnios & 4 & 1.6 \\
Multiple pregnancy & 3 & 1.2 \\
Placenta previa & 1 & 0.4 \\
Placental abruption & 1 & 0.4 \\
\hline
\end{tabular}

$25.8 \%$ between 31 and 35 weeks, there were 3 newborns who weighed less than $1000 \mathrm{~g}$. In total, 65 children were underweight at birth (Table 4).

Sixty percent of the children measured less than 50 $\mathrm{cm}$ at birth. Eleven presented sepsis $(4.3 \%)$ and there is data in the charts regarding perinatal hypoxia in 74 children (29.1\%).

Positive post-natal antecedents were found in 191 children (75.2\%) among which the highest frequency was found in oxygen requirement, phototherapy, exanguinotransfusion, upper respiratory infections, and middle-ear infections, as well as meningitis among other causes according to that observed in Table 5.

Etiological diagnosis. For each patient, a causal diagnosis was done considering for each case what was the principal etiological factor for the hearing loss; nevertheless, in some cases there was concurrence of several significant etiological factors that were included in the definite diagnosis (Table 6).

The first issue coming to our attention is that almost
Table 4

Weeks of gestation and weight at birth

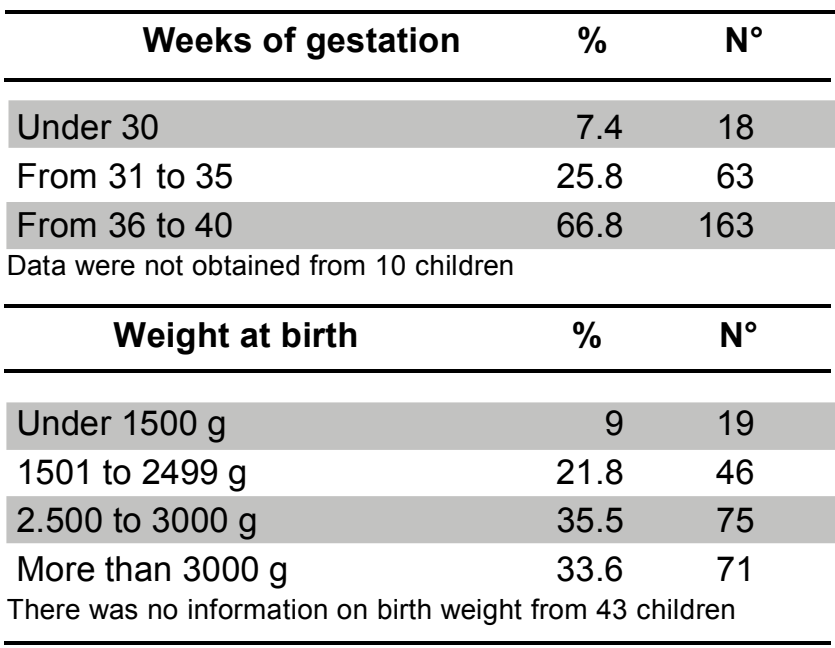

Table 5

Post-natal antecedents

Positive antecedents in $75.2 \%$ (191 cases)

\begin{tabular}{lrr}
\hline & $\mathbf{N}^{\circ}$ & $\%$ \\
\hline Oxygen & 79 & 31.2 \\
Respiratory infections & 65 & 25.6 \\
Phototherapy & 47 & 18.5 \\
Exanguinotransfusion & 27 & 10.6 \\
Ototoxic drugs & 18 & 7.1 \\
Otitis media & 17 & 6.7 \\
Bacterial meningitis & 14 & 5.5 \\
ORL malformation & 2 & 0.8 \\
Syndromes & 10 & 3.9 \\
\hline
\end{tabular}

half the children (120) corresponding to $47.2 \%$ have a diagnosis of unknown etiology. There are 31 cases clearly identified as genetic and among these there is a boy with Waardengurg syndrome and three cases identified with alteration of 26-Conexine, as well as two with Trisomy 21.

Rubella and other prenatal infections were the etiological diagnosis in 38 children (rubella 31 , syphilis 4, toxoplasma 1, cytomegalovirus 1, and herpes 1). Events related to perinatal risks: prematurity (19), hyperbilirrubinemia (8), perinatal hypoxia (16), and toxemia (3) (in total $18.1 \%$ of the population) were important etiological factors; while hearing loss was 
Table 6 Etiological diagnosis

\begin{tabular}{lrr}
\hline \multicolumn{1}{c}{ Etiologies* } & N $^{*}$ & \multicolumn{1}{c}{$\%$} \\
\hline Unknown & 120 & 47.2 \\
STORCH (38) & & \\
$\quad$ Rubella & 31 & 12.2 \\
Toxoplasma & 1 & 0.4 \\
$\quad$ Syphilis & 4 & 1.6 \\
Cytomegalovirus & 1 & 0.4 \\
Herpes & 1 & 0.4 \\
Genetic (1 Wanderburg syndrome, & & \\
2 Trisomy 21, and 3 26-Conexine) & 31 & 12.2 \\
Prematurity & 19 & 7.5 \\
Perinatal hypoxia & 16 & 6.3 \\
\hline Hyperbilirrubinemia & 8 & 3.2 \\
Meningitis & 8 & 3.2 \\
\hline Feverish episodes & 8 & 3.2 \\
\hline Toxemia & 3 & 1.2 \\
\hline Ototoxic drugs & 2 & 0.8 \\
\hline Upper respiratory infection & 1 & 0.4 \\
\hline
\end{tabular}

* Of this group of children, 9 presented double diagnosis; for this reason, the total number of children increases by this proportion

attributed to meningitis in 8 children.

Relationship among variables. Upon verifying the degree of hearing loss in children in relationship to gender, it was found that $53.6 \%$ of the girls had profound hearing loss of the right ear and $57.3 \%$ of them had the same degree of hearing loss in the left ear; while the boys revealed the same type of hearing loss in lower percentages for the right ear $(46.5 \%)$ and for the left ear $(47.8 \%)$. This does not constitute a statistically significant difference between the degree of hearing loss and gender.

No gender differences are noted with family antecedents related to delayed or altered language. When analyzing the antecedent of hypoacusis, we found that boys have more antecedents for hypoacusis (18.8\%) than the girls (11.1\%), yielding p: 0.068. In antecedents related to STORCH and other prenatal factors, no differences were found between boys and girls.

Infection of respiratory pathways was significantly more frequent in boys (30.6\%) than in girls (19.1\%) with p:0.026. The presence of identifiable syndromes like Gregg's and Down's syndromes, and others was found most frequent in females tan in males with $\mathrm{p}$ : 0.039 . There was no significant correlation between the etiological diagnosis and the gender of the children.

\section{DISCUSSION}

The results obtained reveal an important frequency of positive antecedents in the pre-, peri-, and post-natal stages, which could have been triggering or coadjuvant factors of the hearing loss. Likewise, several of these factors converged on particular cases of children at high-risk because of their gestation conditions, birth, and perinatal period.

Upon reviewing family antecedents, these were positive in $55.5 \%$ of the cases. Hypoacusis was found as a factor present in the family, which substantiates the risk of hearing loss in children due to genetic factors, as well as delayed language that can be associated to hearing losses and unspecified neurological pathology.

In $63.4 \%$ of the children, prenatal antecedents are positive and among these the greatest relevance is related to STORCH-type infections with rubella being the most frequent ( 30 children). We found 10 cases of unspecified viruses that could correspond to both undiagnosed rubella and cytomegalovirus. Blood hypertension in the form of preeclampsia or toxemia and the threat of abortion during the first trimester constituted an equally frequent risk factor. Although there are reports of ingestion of medications in an important number of mothers, in general these correspond to vitamins, iron, and broad-spectrum antibiotics like ampicillin, amoxicillin, and others that are not related to deleterious effects in the fetus.

In many cases, there is history of prematurity and underweight, as well as hypoxia and hyperbilirrubinemia sufficiently important to have required phototherapy or exanguinotransfusion and support oxygen.

The infectious causes during the early period of the newborn and their complications, along with exposure to ototoxic medications, also constitute risk factors for hearing loss.

Upon conducting a definite diagnosis, we kept in mind the causal factor in each case that weighed more in the history, aside from the clinical and para-clinical exams done at different stages of the pregnancy and the post-natal period. A total of $47.2 \%$ of the cases were 
classified as unknown etiology. Only 23 cases were diagnosed as clearly genetic.

According to the authors mentioned, there is evidence of growing numbers of cases reported of unknown etiology, corresponding to non-syndrome genetic causes. Other cases may be the result of infections like CMV, considered more and more an important etiological factor for hearing loss and that may go unnoticed from a clinical point of view. In many cases, when not finding relevant data complementary exams are not performed and there is no confirmation if the loss is due to a pre or perinatal infection.

If we compare the data herein reported with the screening studies conducted by Tamayo ${ }^{12}$ in centers for individuals with hearing deficiencies in the nation, we can note that in the figures reported in her study there is prevalence for the diagnosis of congenital Rubella in $30 \%$ of the population and in the group studied at the Fundación CINDA that percentage, although still important as an etiological factor, only constitutes $12.2 \%$ of the population. It is also possible that some of the causes defined as unknown may correspond to undiagnosed rubella and if the recommended rear-ofthe-eye exam had been performed on these children as a fundamental part of the exam, more cases would have been found attributable to this cause.

Vaccination campaigns against rubella, carried out as part of the primary prevention policy by the Ministerio de la Protección Social (Colombian Ministry of Social Protection) since August 2005, are still not reflected in the current results.

The $7.5 \%$ of children whose etiology is based on prematurity and all the risk factors underlying to this condition can generate false hypoacusis cases that corresponded to early stages of hearing maturity, as stated in the study by Talero et al. ${ }^{15}$

The important percentage of antecedents related to pre and perinatal risk factors highlight the importance of improving controls to mothers during gestation.

The definition of the epidemiological characteristics of a population with a specific pathology, and in this case in particular with hearing losses, determines the effects of health policies and supports plans aimed at carrying out primary prevention.

The etiology of hearing loss permits knowing the origin of the alteration and determining the consequences in terms of the functional development of the individual's hearing and, hence, of communication. It is clear in the data reported in this study that there is a high percentage of infectious causes like hypoxia and hyperbilirrubinemia, where the compromise is not exclusively in the hearing, but which is associated with neurologicaltype alterations that may affect -to a greater extent- the child's communicative development. Etiologies of genetic or ototoxic type that generate a specific alteration of hearing permit foreseeing what will be the therapeutic focus and the prognosis in each patient, bearing in mind the different tendencies of rehabilitation in hearing deficiencies.

Conflict of interest. None of the authors has conflicts of interest related to this study.

\section{REFERENCES}

1. Li XC, Friedman RA. Nonsyndromic hereditary hearing loss. Otolaryngol Clin North Am. 2002; 35: 275-85.

2. Mehl AL, Thomson V. The Colorado newborn hearing screening project, 1992-1999: on the threshold of effective population-based universal newborn hearing screening. Pediatrics. 2002; 109: E7.

3. Morton CC, Nance WC. Newborn hearing screening- a silent revolution. $N$ Engl J Med. 2006; 3542: 151-64.

4. Debena K, Janssens de Varebekeb S, Coxb T, Van de Heyning P. Epidemiology of hearing impairment at three Flemish institutes for deaf and speech defective children. Int J Pediatr Otorhinolaryngol. 2003; 67: 969-75.

5. Gruss I, Berlin M, Greenstein T, Yagil Y, Beiser M. Etiologies of hearing impairment among infants and toddlers: 1986-1987 vs. 2001. Int J Pediatr Otorhinolaryngol. 2007; 71: 1587-9.

6. Madriz J. Hearing Impairment in Latin America: inventory of limited options and resources. Audiology. 2000; 39: 212-20.

7. De Nobrega M, Weckx LL, Juliano Y. Study of the hearing loss in children and adolescents, comparing the periods of 1990-1994 and 1994-2000. Int J Pediatr Otorhinolaryngol. 2005; 69: 829-38.

8. Vicepresidencia de la República. Documento Técnico UIS049.95. Sistema Nacional de Información sobre Discapacidad. Bogotá: Vicepresidencia de la República, Consejería Presidencial de Política Social, Ministerio de Educación Nacional, Pontificia Universidad Javeriana, Corporación Interinstitucional de Rehabilitación; 1995.

9. Mencher GT, Madriz Alfaro JJ. Prevalence of sensorineural hearing loss in children in Costa Rica. Audiology. 2000; 39: 278-83.

10. Samileh N, Ahmad S, Mohammad F, Framarz M, Azardokht $\mathrm{T}$, Jomeht E. Role of cytomegalovirus in sensorineural hearing loss of children: A case-control study Tehran, Iran. Int $J$ Pediatr Otorhinolaryngol. 2008; 72: 203-8.

11. Du Y, Xihong W, Liang L. Mechanism of bacterial meningitis-related deafness. Drug discovery today: disease mechanisms 
Drug Discov Today Dis Mech. 2006; 3: 115-8.

12. Tamayo ML, García N, Gelves N, Morales L, Flórez S, Medina D. Rubeola y sordera en Colombia. Hallazgos durante un tamizaje nacional en institutos para sordos. RevMed. 2008; 30: 167-74.

13. Position Statement: principles and guidelines for early hearing detection and intervention programs joint committee on infant hearing. Pediatrics. 2007; 120: 898-921.
14. Ross J, Downs M. Auditory disorders in school children: the law, identification, and remediation. 4th ed. Ross J, Downs M (eds.). New York: Thiememedical; 2004.

15. Talero C, Carvajalino I, Samper B, Ibañez M. Delayed auditory pathway maturation in the differential diagnosis of hypoacusis in young children. Int J Pediatr Otorhinolaryngol. 2008; 72 : 519-27. 